\title{
Corrigendum: Reconstruction and Functional Annotation of P311 Protein-Protein Interaction Network Reveals Its New Functions
}

\author{
Song Wang ${ }^{1}$, Xiaorong Zhang ${ }^{1}$, Fen Hao ${ }^{1}$, Yan $\mathrm{Li}^{2}$, Chao Sun ${ }^{3}$, Rixing Zhan ${ }^{1}$, Ying Wang ${ }^{1}$, \\ Weifeng $\mathrm{He}^{1}$, Haisheng $\mathrm{Li}^{1,4 *}$ and Gaoxing Luo ${ }^{1 *}$ \\ ${ }^{1}$ Institute of Burn Research, State Key Laboratory of Trauma, Burn and Combined Injury, Southwest Hospital, Third \\ Military Medical University, Chongqing, China, ${ }^{2}$ Laboratory Center of Southwest Hospital, Third Military Medical University, \\ Chongqing, China, ${ }^{3}$ The Sixth Resignation Cadre Sanatorium of Shandong Province Military Region, Qingdao, China, \\ ${ }^{4}$ The 324th Hospital of Chinese People's Liberation Army, Chongqing, China
}

OPEN ACCESS

Approved by:

Frontiers Editorial Office,

Frontiers Media SA, Switzerland

*Correspondence:

Haisheng Li

lee58427@163.com

Gaoxing Luo

logxw@yahoo.com

Specialty section:

This article was submitted

to Bioinformatics and

Computational Biology,

a section of the journal

Frontiers in Genetics

Received: 31 July 2019 Accepted: 07 August 2019 Published: 06 November 2019

Citation:

Wang S, Zhang X, Hao F, Li Y,

Sun C, Zhan R, Wang Y, He W, Li H and Luo G (2019) Corrigendum:

Reconstruction and Functional Annotation of P311 Protein-Protein

Interaction Network Reveals

Its New Functions.

Front. Genet. 10:818.

doi: 10.3389/fgene.2019.00818
Keywords: P311, protein-protein interaction networks, inflammatory response, cell proliferation, coagulation

\section{A Corrigendum on:}

Reconstruction and Functional Annotation of P311 Protein-Protein Interaction Network Reveals Its New Functions

By Wang S, Zhang X, Hao F, Li Y, Sun C, Zhan R, Wang Y, He W, Li H and Luo G (2019) Front. Genet. 10:109. doi: 10.3389/fgene.2019.00109

There is an error in the Funding statement. The correct number for "China's NSFC grants program" is "81630055." A correction has therefore been made to the Funding statement and should read:

"This work was supported by grants from China's NSFC grants program (81630055)."

Additionally, in the original article, the reference for "Becker et al., 2011" was incorrectly written as "Becker, E., Robisson, B., Chapple, C. E., Guénoche, A., and Brun, C. (2011). Multifunctional proteins revealed by overlapping clustering in protein interaction network. Bioinformatics 28, 84-90. doi: 10.1093/bioinformatics/btr621". It should be "Becker, E., Robisson, B., Chapple, C. E., Guénoche, A., and Brun, C. (2012). Multifunctional proteins revealed by overlapping clustering in protein interaction network. Bioinformatics 28, 84-90. doi: 10.1093/bioinformatics/btr621".

Lastly, the citation of Becker's work was missing in the Supplementary Material 4. Corrections have been made by placing a copy of the code from Becker et al., Boinformatics, 2012 Jan 1;28(1):8490 , in the supplementary material along with an edited README file. Thus, corrections have also been made to the Materials and Methods, subsection OCG (Overlapping Cluster Generator) Algorithm, by removing the last sentence, which was redundant and to the first paragraph:

"The OCG algorithm was carried out by the software available in (Becker et al., 2012) (Supplementary Material 4)." 
The authors apologize for these errors and state that they do not change the scientific conclusions of the article in any way. The original article has been updated.

\section{ACKNOWLEDGMENTS}

We wish to thank Prof. Gregory A. Taylor from the Duke University Medical Center for kindly providing the P311 KOmice.

\section{SUPPLEMENTARY MATERIAL}

The Supplementary Material for this article can be found online at: https://www.frontiersin.org/articles/10.3389/fgene.2019.00818/ full\#supplementary-material

Copyright (c) 2019 Wang, Zhang, Hao, Li, Sun, Zhan, Wang, He, Li and Luo. This is an open-access article distributed under the terms of the Creative Commons Attribution License (CCBY). The use, distribution or reproduction in other forums is permitted, provided the original author(s) or licensor are credited and that the original publication in this journal is cited, in accordance with accepted academic practice. No use, distribution or reproduction is permitted which does not comply with these terms. 